\title{
Hindbrain Cocaine- and Amphetamine-Regulated Transcript Induces Hypothermia Mediated by GLP-1 Receptors
}

\author{
Karolina P. Skibicka, Amber L. Alhadeff, and Harvey J. Grill \\ Graduate Group of Psychology and Graduate Group of Neuroscience, University of Pennsylvania, Philadelphia, Pennsylvania 19104
}

Cocaine- and amphetamine-regulated transcript (CART) peptides are widely distributed throughout the neuraxis, including regions associated with energy balance. CART's classification as a catabolic neuropeptide is based on its inhibitory effects on feeding, coexpression with arcuate nucleus proopiomelanocortin neurons, and on limited analysis of its energy expenditure effects. Here, we investigate whether (1) caudal brainstem delivery of CART produces energetic, cardiovascular, and glycemic effects, (2) forebrain-caudal brainstem neural communication is required for those effects, and (3) glucagon-like peptide-1 receptors (GLP-1Rs) contribute to the mediation of CART-induced effects. Core temperature (Tc), heart rate (HR), activity, and blood glucose were measured in rats injected fourth intracerebroventricularly with CART $(0.1,1.0$, and $2.0 \mu \mathrm{g})$. Food was withheld during physiologic recording and returned for overnight measurement of intake and body weight. CART induced a long-lasting $(>6 \mathrm{~h})$ hypothermia: $\mathrm{a} 1.5^{\circ} \mathrm{C}$ and $1.6^{\circ} \mathrm{C}$ drop in Tc for the 1.0 and $2.0 \mu \mathrm{g}$ doses. Hindbrain CART application reduced food intake and body weight and increased blood glucose levels; no change in HR or activity was observed. Supracollicular decerebration eliminated the hypothermic response observed in intact rats to hindbrain ventricular CART, suggesting that forebrain processing is required for hypothermia. Pretreatment with the GLP-1R antagonist (exendin-9-39) in control rats attenuated CART hypothermia and hypophagia, indicating that GLP-1R activation contributes to hypothermic and hypophagic effects of hindbrain CART, whereas CART-induced hyperglycemia was not altered by GLP-1R blockade. Data reveal a novel function of CART in temperature regulation and open possibilities for future studies on the clinical potential of the hypothermic effect.

\section{Introduction}

Cocaine- and amphetamine-regulated transcript (CART) neuropeptides were initially localized to the striatum and nucleus accumbens, regions associated with reward, motivation, and addiction (Douglass and Daoud, 1996). Later, CART synthesis was described in regions associated with energy balance control including the arcuate and paraventricular hypothalamus, nucleus tractus solitarius (NTS), and vagal afferent neurons (Koylu et al., 1997, 1998; Broberger, 1999; Broberger et al., 1999; Vrang et al., 1999a,b). In arcuate hypothalamic neurons, CART is coexpressed with proopiomelanocortin (POMC), whose cleavage product, $\alpha$-MSH, is a major catabolic contributor to energy balance (Butler and Cone, 2002; Cone, 2005). Leptin upregulates and food deprivation downregulates hypothalamic expression of both POMC and CART (Kristensen et al., 1998). Melanocortin receptor stimulation produces hypophagia, hyperglycemia, hyperthermia, tachycardia, and increased activity (Fan et al., 2000; Gutiérrez-Juárez et al., 2004; Skibicka and Grill, 2008). Other studies reveal that forebrain ventricular CART delivery decreases food intake and, in conjunction with the findings just described,

Received Dec. 24, 2008; revised March 30, 2009; accepted April 21, 2009

This work was supported by National Institutes of Health Research Grant DK-21397 (to H.J.G.) and National Research Service Award NS-059254 (to K.P.S.). We thank Matt Hayes for his editorial comments and Theresa Leichner for her technical assistance.

The authors declare no competing financial interests.

Correspondence should be addressed to Karolina P. Skibicka, Graduate Group of Psychology and Graduate Group of Neuroscience, University of Pennsylvania, Philadelphia, PA 19104. E-mail: skibicka@mail.med.upenn.edu. DOI:10.1523/JNEUROSCI.6144-08.2009

Copyright $\odot 2009$ Society for Neuroscience $\quad$ 0270-6474/09/296973-09\$15.00/0 lead to the idea that CNS CART effects on energy balance are catabolic in nature (Kristensen et al., 1998; Kuhar et al., 2000; Rogge et al., 2008). The energy expenditure effects of CART are, however, insufficiently investigated. The experiments reported here contribute to a developing perspective that the functional effects of CNS CART signaling on energy balance are not consistent with a catabolic role of $\mathrm{CART}_{55-102}$, as they revealed a hypothermic effect whose mediating neural pathway is described.

Central CART administration (forebrain ventricle) suppresses and blockade of CNS CART signaling with ventricular antiserum delivery increases food intake (Kristensen et al., 1998). Direct hypothalamic CART administration, however, elicits hyperphagia which contrasts with the hypophagia observed with ventricular delivery (Abbott et al., 2001; Smith et al., 2008). This disparity between the direction of effect for ventricular versus direct hypothalamic CART administration suggests that the anorectic action of CART is mediated by extra-hypothalamic sites. In fact, several studies show that hindbrain ventricular [fourth intracerebroventricular (v.)] delivery of CART produces anorexia (Aja et al., 2001b, 2002; Zheng et al., 2001, 2002).

Although an indirect measure, the increase in brown adipose UCP-1 expression in response to arcuate and paraventricular nucleus CART delivery (Wang et al., 2000; Kong et al., 2003) indicates a role of hypothalamic CART in thermogenesis and catabolic action. However, the energetic and cardiovascular effects of hindbrain CART stimulation are mostly unexplored (Hwang et al., 2004). CART is detected in several hindbrain regions associated with energy balance/thermoregulation including NTS, parabrachial nucleus (PBN), raphe pallidus, and rostral ventral lateral 


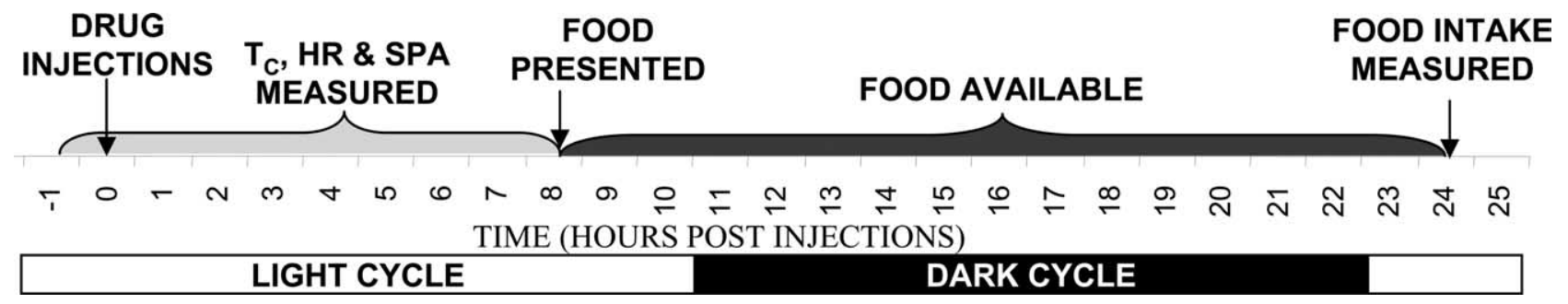

Figure 1. Experimental paradigm used for measurements of TC, HR, SPA, and food intake.

medulla (Dun et al., 2000, 2001). For this reason, our experiments examined the energetic and cardiovascular effects produced by hindbrain (fourth v. and NTS) CART $_{55-102}$ delivery.

Hindbrain glucagon-like peptide-1 receptors (GLP-1Rs) mediate $\mathrm{CART}_{55-102}$-induced hypophagia and neuronal activation [Fos-like immunoreactivity (Fos-Li)] observed in multiple hindbrain sites (Aja et al., 2006). Some of these Fos-Li-expressing nuclei are also relevant to thermoregulation. Therefore, our experiments also assessed whether hindbrain GLP-1Rs contribute the energy expenditure effects of hindbrain $\mathrm{CART}_{55-102}$ stimulation.

\section{Materials and Methods \\ Subjects \\ Male Sprague Dawley rats (Charles River Laboratories), weighing $300-$ $400 \mathrm{~g}$ (10-12 weeks old) at surgery and housed individually in plastic bins under a $12 \mathrm{~h}$ light/dark cycle (8:00 A.M. lights on), participated in the five experiments described below. Pelleted food (Purina 5001) and water were available ad libitum, unless otherwise noted. All procedures conformed to the institutional standards of animal care and use commit- tee (University of Pennsylvania).}

\section{Surgery}

Rats were anesthetized with ketamine $(90 \mathrm{mg} / \mathrm{kg})$, xylazine $(2.7 \mathrm{mg} / \mathrm{kg})$, and acepromazine $(0.64 \mathrm{mg} / \mathrm{kg})$ delivered intramuscularly.

Fourth and third $v$. and NTS intraparenchymal cannula implantation. Rats in experiments 1,3 , and 4 received a fourth v. guide cannula (26 gauge; Plastics One) with its tip stereotaxically positioned $2.0 \mathrm{~mm}$ above the fourth ventricle (coordinates: on the midline, $2.5 \mathrm{~mm}$ anterior to the occipital suture, and $4.5 \mathrm{~mm}$ ventral to the dura, with injector aimed 6.5 $\mathrm{mm}$ ventral from dura). Rats in experiment 3 also underwent a decerebration surgery. Drug injections to the fourth v. at volumes used in our experiments have been shown to be confined to the hindbrain regions without stimulation of regions rostral to the fourth v. (Flynn and Grill, 1985; Blevins et al., 2004; Fan et al., 2004; Hayes et al., 2009). A second group of rats in experiment 4 received a third v. guide cannula (coordinates: on the midline, $2 \mathrm{~mm}$ posterior to bregma, and $5.5 \mathrm{~mm}$ ventral to dura mater, with injector aimed $7.5 \mathrm{~mm}$ ventral to dura). Rats in experiment 5 received a cannula positioned $2.0 \mathrm{~mm}$ above the medial NTS [coordinates: $0.5 \mathrm{~mm}$ from the midline, on occipital suture, $5.9 \mathrm{~mm}$ ventral to skull; placement as described previously by Hayes et al. (2009)]. Cannulas were attached to the skull with dental acrylic and jeweler's screws and closed with an obturator as described previously (Fan et al., 2000; Gutiérrez-Juárez et al., 2004; Skibicka and Grill, 2008).

Decerebration surgery. Supracollicular decerebration was performed in two hemitransection stages separated by at least 1 week, as described previously (Grill and Norgren, 1978). Decerebrate rats received fourth v. cannulas and telemetric transponders (described below) during the second hemisection surgery. Pair-fed (gavage-fed) neurologically intact control rats were also anesthetized on two occasions and implanted with fourth v. cannulas and telemetric transponders during the second surgery. Rats recovered for at least 1 week before the experiment started. The completeness of the intended transection was verified histologically after the experiment. Only rats with a histologically verified complete transection were included in the data analyses.

Telemetric transponder surgery. Telemetric transponders (HRC $4000 \mathrm{Vi-}$
talView; Mini Mitter/Respironics) for recording core temperature (Tc), heart rate (HR), and spontaneous physical activity (SPA) were inserted into the abdominal cavity, with the leads positioned subcutaneously and secured to the chest muscles on either side of the heart with sutures.

\section{Experimental procedures}

Cannula position verification. At least $7 \mathrm{~d}$ after surgery, all brain cannula placements were assessed by measurement of the sympathoadrenalmediated glycemic response to central injection of 5-thio-D-glucose [210 $\mu \mathrm{g}$ in $2 \mu \mathrm{l}$ artificial CSF (aCSF; Harvard Apparatus) for third and fourth v. and $21 \mu \mathrm{g}$ in $0.1 \mu \mathrm{l}$ for NTS] (Ritter et al., 1981). A postinjection elevation of at least $100 \%$ of baseline plasma glucose level was required for subject inclusion.

Habituation training. Before the start of experimental testing, rats were acclimated to the handling and injection procedures used in a given experiment.

Food intake and body weight monitoring. As described in Figure 1, food was removed at the time of injections (early in the light cycle) and returned $8 \mathrm{~h}$ later, late in the light phase. Thus, food was not available during the period of energetic/sympathetic response measurement. Food intake and body weight measurements were made $24 \mathrm{~h}$ after the injection of drug. Given this design, all noted differences in food intake reflect longer latency effects of CART (i.e., intake from 8 to $24 \mathrm{~h}$ after injection). For ad libitum-feeding rats, food was always available during the dark cycle, and a minimum of $48 \mathrm{~h}$ was allotted between experimental testing for all animals.

Blood glucose response measurements. Blood glucose was measured before ventricular injections and at 30,60,120, and $240 \mathrm{~min}$ after injection by collecting a drop of tail blood and placing it in a standard glucometer (Accucheck; Roche Diagnostics). Food (chow) was not available during the blood glucose measurements; it was returned immediately after the $240 \mathrm{~min}$ measurement and measured $24 \mathrm{~h}$ after drug injection.

\section{Experiment 1}

To determine the energy expenditure and food intake effects of hindbrain CART $_{55-102}$ stimulation, rats $(n=23)$ received fourth $\mathrm{v}$. vehicle injections (1 $\mu \mathrm{l}$ aCSF) counterbalanced with one dose of CART $\left(\mathrm{CART}_{55-102}\right.$; American Peptide Company): $0.1 \mu \mathrm{g}(19 \mathrm{pmol}, n=4), 1.0$ $\mu \mathrm{g}(190 \mathrm{pmol}, n=9), 2.0 \mu \mathrm{g}(380 \mathrm{pmol}, n=10)$. CART $_{55-102}$ was chosen for this study as this peptide fragment has been previously shown to have physiological effects when applied to the hindbrain (Aja et al., 2001a,b, 2002, 2006; Zheng et al., 2001, 2002) and also effects on thermogenesis when applied to paraventricular nucleus (PVN) (Wang et al., 2000). Core temperature, HR, and SPA were recorded telemetrically for $1 \mathrm{~h}$ before injections and $8 \mathrm{~h}$ after injections every $5 \mathrm{~min}$ (Tc, SPA) or $30 \mathrm{~s}$ (HR). Food intake and body weight were recorded $24 \mathrm{~h}$ after injections. To assess whether hindbrain CART induced effects on glycemia, changes in blood glucose were measured after fourth $\mathrm{v}$. application of CART (2.0 $\mu \mathrm{g})$ in a separate group of rats $(n=12)$.

\section{Experiment 2}

All rats $(n=11)$ received $2.0 \mu \mathrm{g}$ of CART or vehicle (saline) intraperitoneally. The purpose of this experiment was to test whether any of the effects of CART seen with the central treatment can be ascribed to diffusion of the peptide out of CNS and stimulation of receptors in the periphery. Energy expenditure and food intake measurements were made as described in experiment 1 . 
Experiment 3

To begin to define the neurocircuitry mediating the energy expenditure effects of hindbrain CART delivery the chronic decerebrate (CD) rat model was used. A lack of effect in CD rats compared with intact controls would indicate the requirement for forebrain neurocircuitry for mediation of a given effect. CD rats were maintained on a liquid diet (AIN $76 \mathrm{~A}$ rodent diet; Research Diets; $9 \mathrm{ml}$, gavagefed four times daily) as they do not feed spontaneously. This maintenance regimen provides $79 \mathrm{kcal} / \mathrm{d}$ and adequate hydration; rats gain weight on this regimen. Feedings were separated by intervals of at least $2 \mathrm{~h}$. CD and gavage-fed intact control rats were maintained on this feeding paradigm, except during experimental testing when animals were only fed three times: once $2 \mathrm{~h}$ before experiments commenced and twice after the experimental testing. Core temperature of CD rats is more variable than that of control rats. Rectal temperature was measured at each gavage feeding, and rats were cooled or heated if Tc was $<34.0$ or $>38.5^{\circ} \mathrm{C}$ (except during experimental testing). Rats received two doses of CART $(1.0$ and $2.0 \mu \mathrm{g})$ and vehicle in a counterbalanced design over 3 separate testing days (separated by a minimum of $48 \mathrm{~h}$ ). Core temperature, HR, and SPA were recorded telemetrically for $1 \mathrm{~h}$ before injections and $8 \mathrm{~h}$ after injections.

\section{Experiment 4}

To determine whether the CART-induced changes in energy expenditure are mediated by GLP-1Rs, all rats ( $n=9$, third v.; $n=7$, fourth v.) received four of the following ventricular injections counterbalanced over 4 testing days and separated by at least $48 \mathrm{~h}$ : (1) aCSF; (2) CART $1.0 \mu \mathrm{g}$; (3) CART $1.0 \mu \mathrm{g}$ plus exendin-9 $100 \mu \mathrm{g}$ (exendin-9-39; American Peptide Company); (4) exendin-9 $100 \mu \mathrm{g}$. Exendin-9 dose selection was based on Aja et al. (2006). Core temperature, HR, and SPA were recorded telemetrically for $1 \mathrm{~h}$ before injections and $8 \mathrm{~h}$ after injections. To determine if the CART-induced changes in blood glucose and food intake are mediated by GLP-1Rs, in a separate group of rats $(n=10)$, blood glucose levels, $24 \mathrm{~h}$ food intake and body weight change were measured after (1) aCSF; (2) CART $2.0 \mu \mathrm{g}$; (3) CART $2.0 \mu \mathrm{g}$ plus exendin-9 $100 \mu \mathrm{g}$; (4) exendin-9 $100 \mu \mathrm{g}$. Some effects of CART (e.g., gastric emptying) are mediated by corticotrophin-releasing factor receptors (CRF-Rs) and not GLP-1Rs (Smedh and Moran, 2003), indicating that CART exerts its CNS action through at least two separable neuropeptide pathways. To determine if the CARTinduced changes in blood glucose and food intake are mediated by CRF-Rs, in a separate group of rats $(n=8)$, blood glucose levels were measured after (1) aCSF; (2) CART $2.0 \mu \mathrm{g}$; (3) CART $2.0 \mu \mathrm{g}$ plus CRF antagonist $38 \mu \mathrm{g}$ [ $\alpha$-helical CRF-(9-41); Sigma-Aldrich]; (4) CRF(9-41). CRF-(9-41) dose selection was based on Smedh and Moran (2003). This dose was effective in blocking CART-induced inhibition of gastric emptying; it was also shown to have no effects on CART hypophagia (Smedh and Moran, 2003).
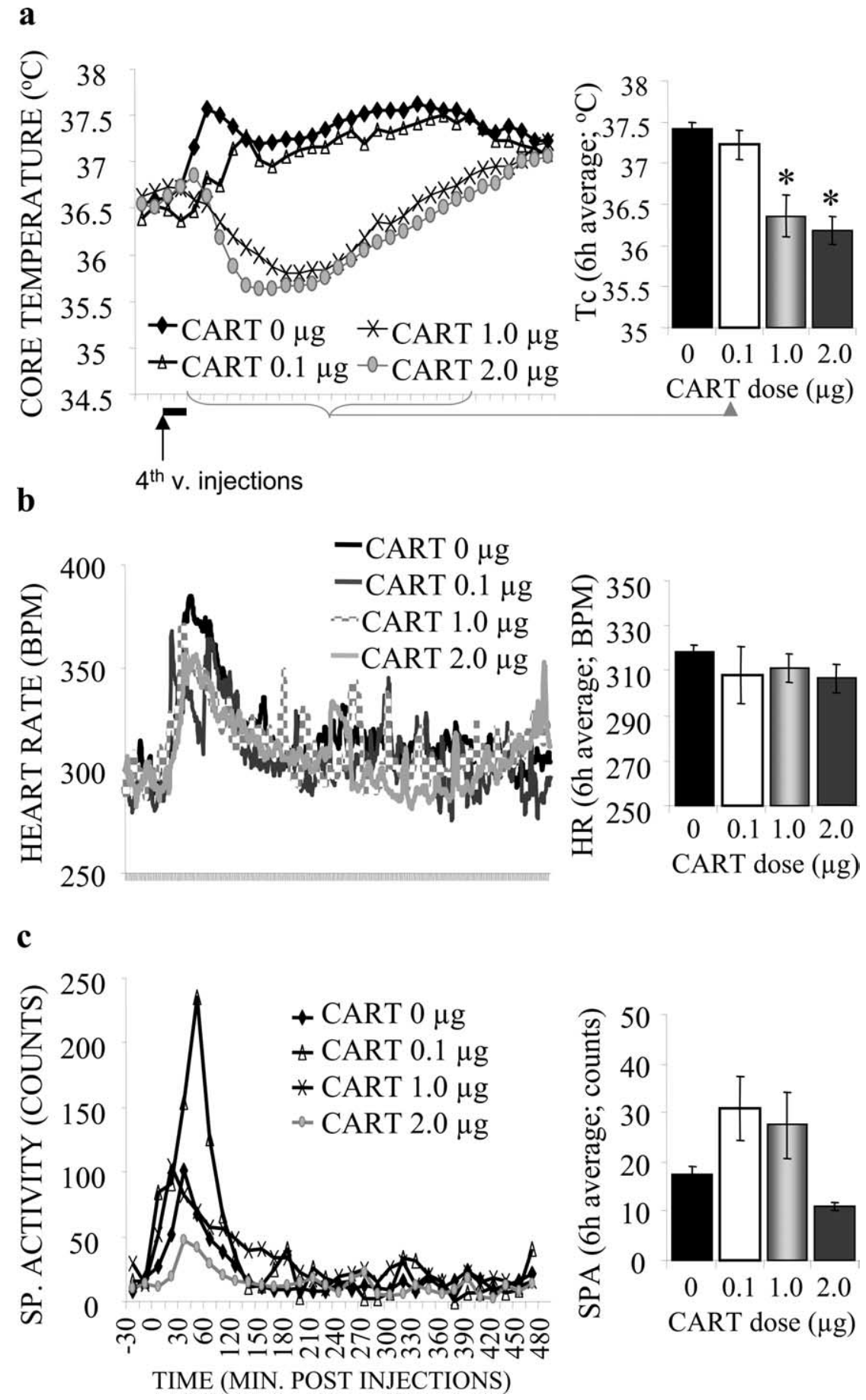

Figure 2. Effect of hindbrain CART stimulation (fourth v. injection) on Tc (a), HR (b), and SPA (c). Line graphs represent across-rat average parameter measurements through the $8 \mathrm{~h}$ recording period. The bracketed time period on the line graph $x$-axis indicates the periods used in the histograms. The histograms provide $6 \mathrm{~h}$ postinjection averages $+\mathrm{SEM}$ for each parameter at each dose. ${ }^{*} p<0.05$ from vehicle.

\section{Experiment 5}

NTS is innervated by CART fibers and is also a site of thermoregulatory and intake control (Koylu et al., 1997, 1998; Broberger, 1999; Broberger et al., 1999; Vrang et al., 1999a,b). To examine whether the NTS is the hindbrain locus for the energy expenditure and food intake effects of CART observed after fourth v. application, all rats $(n=12)$ received unilateral vehicle injections $(0.1 \mu \mathrm{l}$ aCSF $)$ counterbalanced with one dose of CART: $0.1 \mu \mathrm{g}$ into the parenchyma of the NTS. Energy expenditure, food intake, and body weight were recorded as in experiment 1 . 


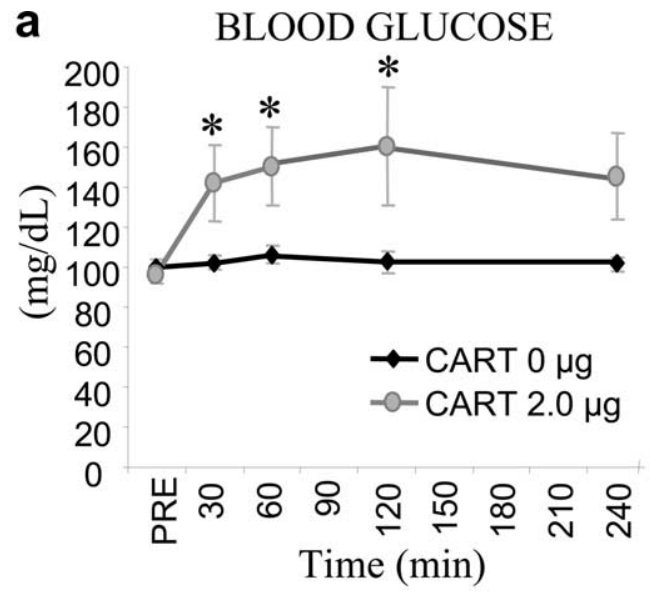

b CHOW INTAKE c BODY WEIGHT.
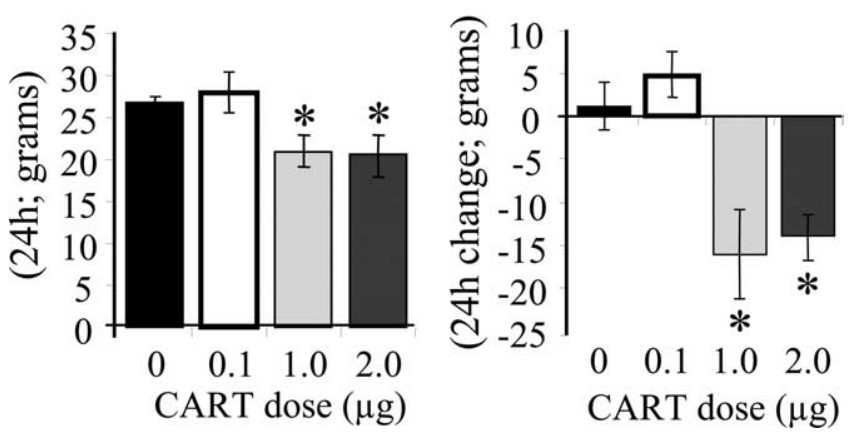

Figure 3. Effect of hindbrain CART stimulation (fourth v. injection) on blood glucose levels $(\boldsymbol{a}), 24 \mathrm{~h}$ food intake $(\boldsymbol{b})$, and $24 \mathrm{~h}$ body weight $(\boldsymbol{c})$. The histograms provide averages $+\mathrm{SEM}$ for each parameter at each dose. ${ }^{*} p \leq 0.05$ from vehicle.

Statistical analysis

Core temperature, HR, and SPA were analyzed by ANOVA on postinjection $6 \mathrm{~h}$ average values of each parameter and followed by Student's $t$ test or Tukey test, as appropriate. Twenty-four hour food intake and body weight were analyzed by ANOVA and followed by $t$ test or Tukey test, as appropriate. All statistical analysis was conducted using STATISTICA software (StatSoft). Differences were considered significant at $p<0.05$.

\section{Results}

\section{Experiment 1}

Core temperature

Fourth ventricular CART injections produced large and longlasting hypothermic responses, with a maximum drop of $0.7^{\circ} \mathrm{C}$, $1.5^{\circ} \mathrm{C}$, and $1.6^{\circ} \mathrm{C}$ in $\mathrm{Tc}$ and a $6 \mathrm{~h}$ average effect size of $-0.2^{\circ} \mathrm{C}(p=$ $0.902),-1.1^{\circ} \mathrm{C}(p<0.0005),-1.3^{\circ} \mathrm{C}(p<0.0005)$ for the 0.1 , 1.0 , and $2.0 \mu \mathrm{g}$ doses, respectively (Fig. $2 a$ ).

\section{Heart rate}

Although heart rate decreased slightly in some rats, this effect was not consistent across all rats, and no significant changes were noted for any of CART doses used (Fig. 2b).

\section{Spontaneous activity}

No significant changes in spontaneous activity were observed (Fig. 2c).

\section{Blood glucose}

Blood glucose was significantly increased after $2 \mu \mathrm{g}$ CART injection at $30(p<0.05), 60(p<0.01)$, and $120(p<0.05)$ min after injection or as area under the curve (AUC; $p<0.05$ ) (Fig. $3 a$ ). a
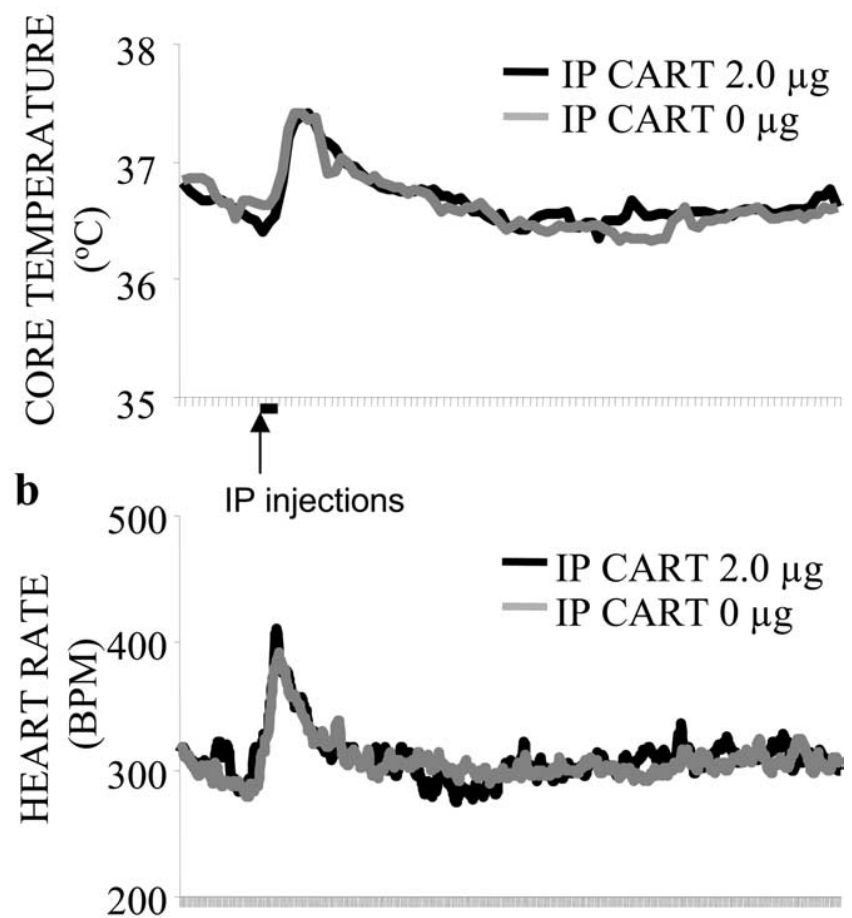

年

200

$\sum^{2} 150$

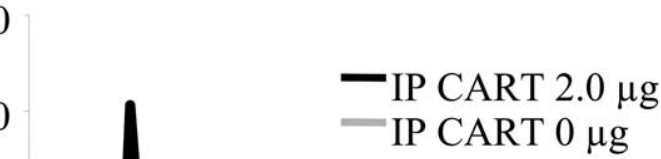

西

穵 100

○ิ

$\begin{array}{lll} & 50 \\ Z & 0 & 0\end{array}$

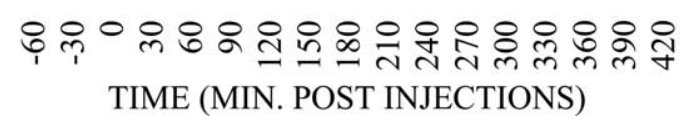

Figure 4. Effect of peripheral CART stimulation [intraperitoneal (IP) delivery] on core temperature $(\boldsymbol{a})$, heart rate $(\boldsymbol{b})$, and spontaneous activity $(\boldsymbol{c})$. Line graphs represent across-rat average parameter measurements through the $8 \mathrm{~h}$ recording period. The histograms provide averages + SEM.

Food intake

Food intake was decreased by the $1.0(p=0.058)$ and $2.0 \mu \mathrm{g}$ $(p<0.05)$ CART doses (food available $8-24 \mathrm{~h}$ after injection) (Fig. 3b).

Body weight

Body weight was also significantly decreased by the $1.0(p<0.05)$ and $2.0 \mu \mathrm{g}(p<0.05)$ CART (Fig. 3c).

\section{Experiment 2}

Peripheral application of CART had no effect on food intake [30.9 $\pm 0.5 \mathrm{~g}$ on vehicle vs $30.7 \pm 0.8 \mathrm{~g}$ on $2.0 \mu \mathrm{g}$ CART; nonsignificant (ns) ], body weight change $(2.6 \pm 1.4$ g on vehicle vs $0.1 \pm$ $1.5 \mathrm{~g}$ on $2.0 \mu \mathrm{g}$ CART; ns) and any of the measured energy expenditure parameters (Fig. 4). 


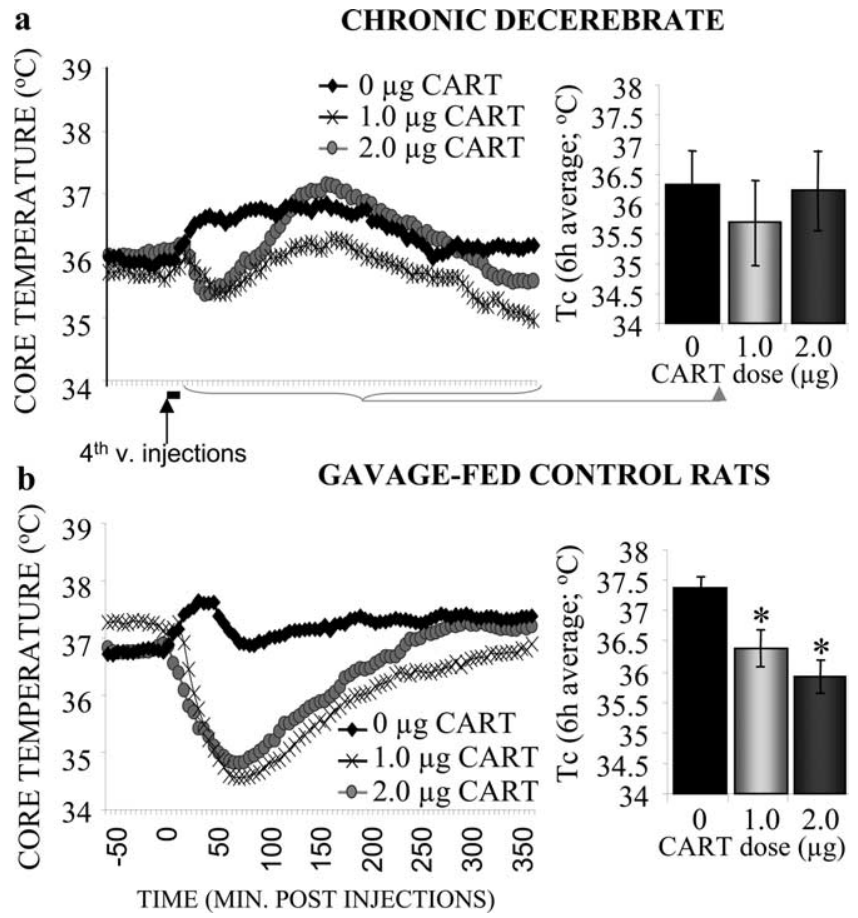

Figure 5. Effect of hindbrain CART stimulation (fourth v. injection) on Tc in chronic decerebrate $(\boldsymbol{a})$ and gavage-fed $(\boldsymbol{b})$ rats. Line graphs represent across-rat average parameter measurements through the $8 \mathrm{~h}$ recording period. The histograms provide $6 \mathrm{~h}$ postinjection averages + SEM for each parameter at each dose. ${ }^{*} p<0.05$ from respective vehicle.

\section{Experiment 3}

\section{Gavage-fed control rats}

Core temperature was significantly decreased by fourth v. CART application at both the $1.0(p<0.05)$ and $2.0 \mu \mathrm{g}(p<0.0005)$ doses.

\section{$C D$ rats}

There was no significant hypothermia noted after CART application in this group (Fig. 5). To extract any possible short-term temperature effects that might have been present in the CD rats, data were reanalyzed (on both CD and gavage-fed control rats) by a two-way ANOVA looking at the interaction of time $(30 \mathrm{~min}$ periods) and drug. This analysis yielded a significant effect of drug $(p=0.005)$, time $(p<0.0005)$, and a significant interaction $(p<0.0005)$ in gavage controls. However, there were no significant effects in CDs [drug $(p=0.41)$, time $(p=0.20)$, and drug-time interaction $(p=0.74)]$.

\section{Experiment 4}

Significant hypothermia was noted when $1.0 \mu \mathrm{g}$ of CART was applied alone in the third $(p<0.05)$ or fourth v. $(p<0.05)$. This CART-induced hypothermic response was abolished after hindbrain delivery of the GLP-1R antagonist exendin-9 (100 $\mu \mathrm{g} ; p=$ 0.97 from aCSF, Tc). Exendin-9 application alone was without effect (third v., $p=0.72$; fourth v., $p=0.99$ ) (Fig. 6). Consistent with results from experiment 1 , CART at $2.0 \mu \mathrm{g}$ produced a significant hyperglycemic response when delivered to the fourth $\mathrm{v}$. $(p<0.005)$; this effect was not altered by the exendin-9 treatment $(p<0.005$ from aCSF). Fourth ventricular CART delivery $(2.0 \mu \mathrm{g})$ significantly reduced chow intake $(p<0.001)$; pretreatment with the GLP-1R antagonist attenuated this effect $(p=0.21$ from aCSF). Similarly, the reduction in $24 \mathrm{~h}$ body weight produced by CART fourth v. $(p<0.005)$ was attenuated by exendin-9 pretreatment $(p=0.69)($ Fig. $7 a-d)$. In a separate group of rats, the effect of CRF-R blockade on CART-induced hyperglycemia was evaluated. CART at $2.0 \mu \mathrm{g}$ produced a significant hyperglycemic response when delivered to the fourth $\mathrm{v}$. $(p<0.01)$; this effect was not altered by the CRF- $(9-41)$ treatment $(p<0.05$ from vehicle) (Fig. $7 e, f)$. There was no effect of the CRF- $(9-41)$ alone ( $p=0.99$ from aCSF).

\section{Experiment 5}

Intraparenchymal injection of CART at a dose that was ineffective when applied in the fourth v. $(0.1 \mu \mathrm{g})$ significantly $(p<$ $0.05)$ decreased Tc when applied to the medial NTS parenchyma (Fig. 8a). Only rats with confirmed NTS placement were included in the data analysis (representative injection site is shown in Fig. $8 b$ ). No significant changes were observed in HR, SPA, food intake, and body weight.

\section{Discussion}

Our experiments addressed the hypothesis that CART peptides' effects on energy balance cannot be characterized as simply catabolic in nature. CART peptide was applied to the fourth ventricle (hindbrain directed), the third ventricle (hypothalamus directed), and directly to the NTS parenchyma and its effects on energetic (Tc and activity), cardiovascular (HR), food intake, body weight, and plasma glucose parameters were measured. Our data show that CNS delivery of CART results in a hypothermia. We discuss the hypothermic effect first, the GLP-1R mediation of this response next, and then review the other effects observed.

These are the first data to show that hindbrain CART $_{55-102}$ delivery induced a pronounced and long-lasting hypothermic response $\left(\mathrm{a} 1.5^{\circ} \mathrm{C}\right.$ and $1.6^{\circ} \mathrm{C}$ decrease in Tc for the 1.0 and $2.0 \mu \mathrm{g}$ doses relative to vehicle treatment; $>6 \mathrm{~h}$ duration). Injections of CART into the forebrain ventricle (providing access of drug to forebrain and hindbrain sites attributable to the caudal flow of CSF), hindbrain ventricle, and hindbrain parenchyma (intraNTS) were each effective in decreasing Tc. The potent and long duration of hypothermia triggered by injections selective to the hindbrain ventricle or NTS parenchyma, that bypass forebrain, indicated that CART responsive neurons located within the hindbrain and at least partially within the NTS mediated the hypothermic response. Additional experiments evaluating hypothalamic or forebrain parenchymal sites are needed to directly exclude the possibility of forebrain contribution to the hypothermic response. However, the few published studies that examine the energy expenditure effect of hypothalamic (ARC; PVN) CART injection show responses [increases in brown adipose tissue (BAT) UCP-1] that are typically associated with a hyperthermic action (Wang et al., 2000; Kong et al., 2003). That the thermic response to hypothalamic CART injection is opposite in direction to the current findings strengthens the hypothesis that the hypothermia was mediated by hindbrain CART responsive neurons.

We recently showed (Hayes et al., 2008) that stimulation of hindbrain GLP-1R induces hypothermia similar in duration and size to that produced by CART in the present study. Current data establish that GLP-1 neurons and hindbrain GLP-1Rs are down-

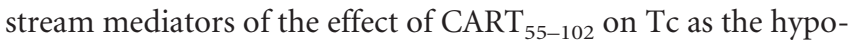
thermic effect of CART was eliminated by blockade of hindbrain GLP-1Rs with exendin 9-39. It is interesting to note that the hypothermic effect of hindbrain GLP-1R stimulation does not require intact forebrain-hindbrain communication as the effect was unaltered by supracollicular decerebration (Hayes et al., 2008). In contrast, we showed here that the hypothermic effect of 
CART requires neural connections between the forebrain and hindbrain, and forebrain processing is required, as the hypothermia was not present in rats with chronic supracollicular transsection. Therefore, the circuitry mediating the hypothermic effect of CART might involve hindbrain neurons responsive to CART that project to the forebrain. The identity of those forebrain-projecting neurons is not known; however, our data showing hypothermia in response to NTS CART stimulation suggests that at least part of CART's effects on temperature is mediated by potential CART receptors located in or near the NTS. NTS neurons project heavily in a rostral manner (e.g., PBN) to nuclei that relay peripheral thermal information to thermoregulatory neurons in the hypothalamic preoptic area (Nakamura and Morrison, 2008). The forebrainrelayed information would be subsequently transmitted back to the hindbrain resulting in putative GLP-1 release from the NTS proglucagon-expressing neurons and subsequent hindbrain GLP-1R stimulation. Once activated, the output pathway after hindbrain GLP-1R activation inducing hypothermia is contained within the hindbrain (Hayes et al., 2008). Several nuclei expressing GLP-1Rs within the hindbrain contain sympathetic premotor neurons (Yamamoto et al., 2002). It is possible that inhibition of those neurons results in the observed hypothermia. Experiments evaluating hindbrain CART and GLP-1 effects on SNS neurons and BAT activity are needed to evaluate this possibility. Another potential mechanism contributing to hypothermia is SNS-mediated vasodilatation. A role of other neurotransmitters (e.g., serotonin and dopamine) that are associated with hypothermic responses (Cryan et al., 2000; Catalina et al., 2002) in this pathway is possible and remains to be investigated.

Although the hypothermic response to hindbrain CART $_{55-102}$ peptide stimulation contrasts with the hyperthermic effect of hindbrain melanocortin receptor stimulation, the anorexia and acute hyperglycemic effects of CART injection are similar to those observed with melanocortin delivery (Fan et al., 2000). The anorexic effect of hindbrain CART stimulation observed here is consistent with several studies (Kristensen et al., 1998; Rogge et al., 2008). Furthermore, Aja et al. (2006) show that GLP-1Rs are downstream of the anorexia triggered by hindbrain CART as measured by alterations in palatable diet (Ensure) intake. Our studies confirm this GLP-1R mediation of anorexic effects of CART and extend the conclusion to effects on consumption of standard chow (food of lesser palatability). We show, for the first time, that acute $\mathrm{CART}_{55-102}$ stimulation increased blood glucose levels. This is consistent with the direction of acute effect of CNS melanocortin stimulation on blood glucose (Fan et al., 2000). Unlike CART's hypothermic and anorexic effect, the hyperglycemic effect was not mediated by hindbrain GLP-1Rs as blockade of hindbrain GLP-1Rs did not alter CART-induced hyperglycemia. $4^{\text {th }} \mathrm{V}$.

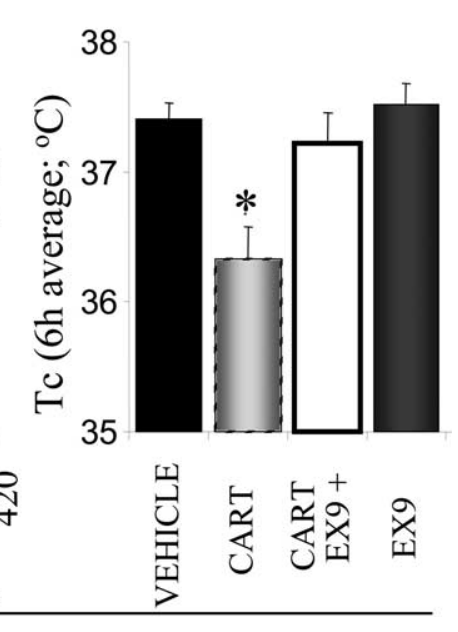

$\rightarrow$ CART -CART + EX9 $\rightarrow-\mathrm{EX} 9$

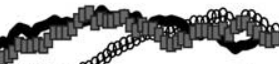

35

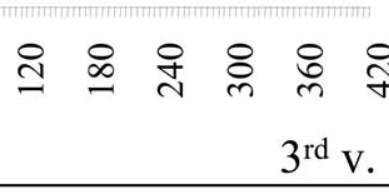

Figure 6. Effect of GLP-1R blockade by exendin 9-39 (100 $\mu \mathrm{g})$ on the CART-induced $(1 \mu \mathrm{g})$ hypothermia with drugs delivered to the fourth $v$. $(\boldsymbol{a})$ third $v(\boldsymbol{b})$. Line graphs represent across-rat average parameter measurements through the $8 \mathrm{~h}$ recording period. The histograms provide $6 \mathrm{~h}$ postinjection averages + SEM for each parameter at each dose. ${ }^{*} p<0.05$ from vehicle.

Other effects of CART (e.g., gastric emptying) are mediated by CRF-Rs (Smedh and Moran, 2003) but not GLP-1Rs. Here, we show that CART-induced hyperglycemia does not require hindbrain CRF-R mediation, indicating that a different mechanism might govern the hyperglycemic effect of CART.

CART peptides are not only widely present in the CNS but also detected in some areas relevant to energy balance outside of the CNS including the adrenal medulla, gut, and pancreas (Thim et al., 1998, 1999; Jensen et al., 1999). To evaluate the potential contribution of CART stimulation outside of the CNS to energetic and anorexic effects of CART, rats were injected intraperitoneally with the highest dose of CART applied in the ventricle. Peripheral CART $_{55-102}$ application did not have any effects on any of the measured parameters, suggesting that effects seen after central CART application do not result from stimulation of potential receptors accessed by intraperitoneal injection.

Our current data, along with those of others [for review, see Kuhar et al. (2000)], suggest that CNS CART peptide plays a role in several anatomically separable circuits. CART stimulation within the cortical and mesolimbic regions elicits reward and motivation responses (Jaworski and Jones, 2006). CART stimulation in the mesolimbic nucleus accumbens produces anorexia (Yang et al., 2005). Hypothalamic CART injection has varied 
a

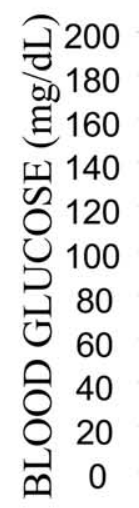

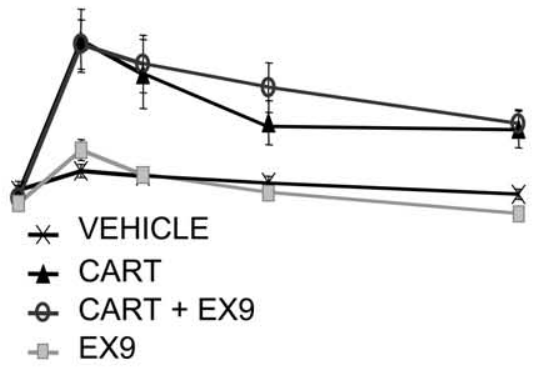

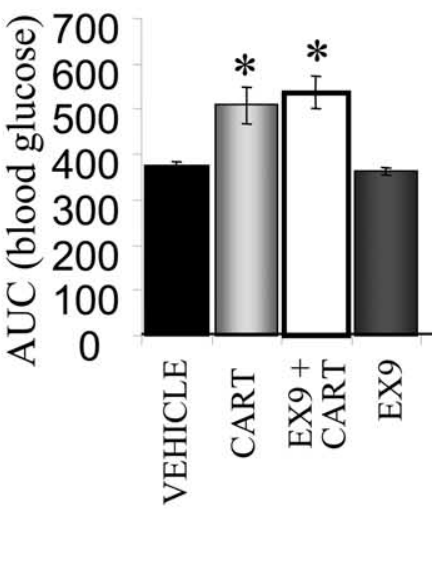

C

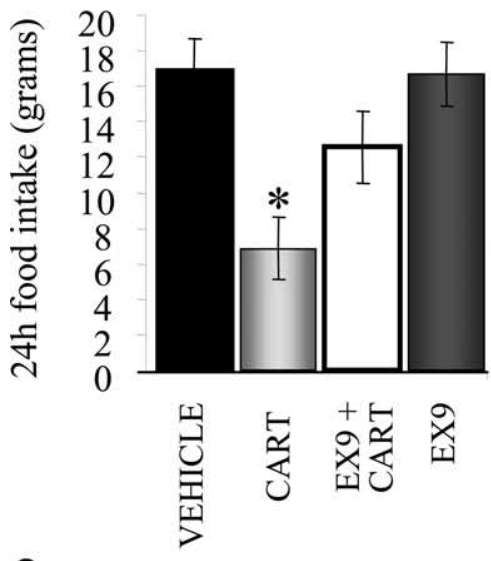

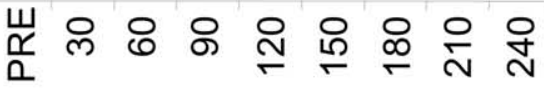 \\ Time post-injection (minutes)}

b

b

d e

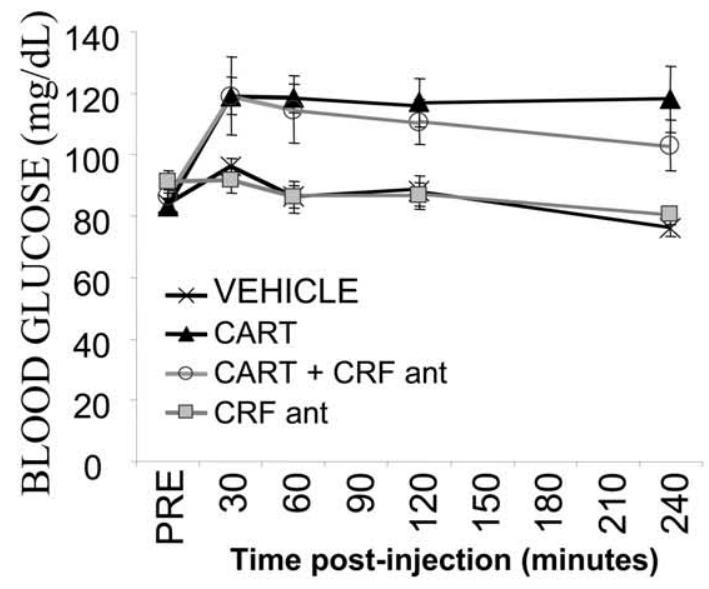

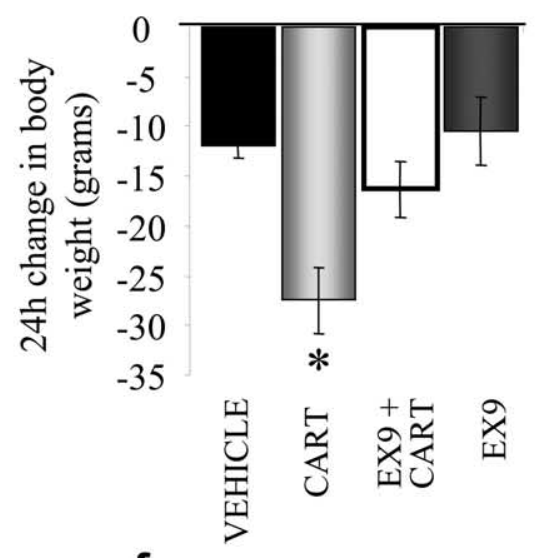

f

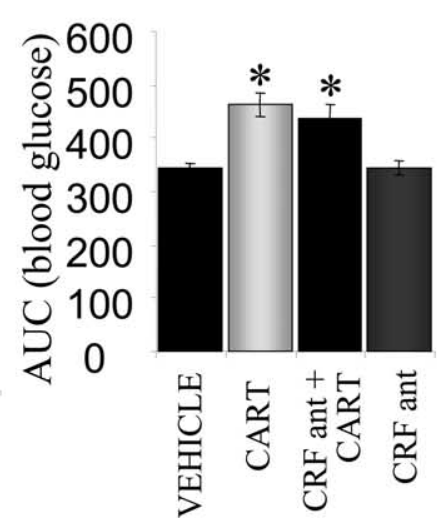

Figure 7. Effect of GLP-1R blockade by exendin 9-39 (100 $\mu \mathrm{g})$ on fourth v. $2 \mu \mathrm{g}$ CART-induced hyperglycemia $(\boldsymbol{a}, \boldsymbol{b})$, hypophagia (c), $24 \mathrm{~h}$ body weight (d), effect of CRF receptor blockade $(\boldsymbol{e}, \boldsymbol{f})$ by CRF antagonist (ant) [38 $\mu \mathrm{g}$ of $\alpha$-helical CRF-(9-41)] on fourth v. CART-induced hyperglycemia. The histograms provide postinjection averages + SEM. AUC * $p<0.05$ from vehicle.

effects on food intake but appears to increase energy expenditure (UCP1 activity) (Wang et al., 2000; Kong et al., 2003). In hypothalamic explants, CART suppresses release of MSH and induces agouti-related protein release (Stanley et al., 2001; Dhillo et al., 2002). In addition, although CART and POMC are coexpressed in the arcuate hypothalamus, CART is also coexpressed with the orexigenic peptide melanin-concentrating hormone in lat-

eral hypothalamic neurons (Broberger, 1999). Hindbrain CART application decreases food intake, gastric emptying (Smedh and Moran, 2003), and as shown here, core body temperature. Further evaluation of the complexity of CART's functional effects and the mediating neurocircuitry awaits the discovery of CART receptors.

The observed hypothermia was not associated with other anabolic indicators. Our measurements included several parameters that are associated with energy expenditure and sympathetic control (Tc, activity, HR). Melanocortin treatment, for example, alters all three parameters in the catabolic direction consistent with increased energy expenditure and sympathetic activation (Fan et al., 2000; Gutiérrez-Juárez et al., 2004; Skibicka and Grill, 2008). CART injection triggered a different pattern of response-hypothermia without alteration in activity and HR. If CART hypothermia is not a part of a coordinated pattern of energy balance effects, then what is the physiological utility of potent and sustained hypothermic response? Several processes have been associated with a marked hypothermia. Conditioned taste aversion (CTA) is often accompanied by a hypothermic response. Some studies (Aja et al., 2002) suggest that CART plays a role in CTA response. Lithium chloride ( $\mathrm{LiCl}$ ), a common inducer of CTAs, produces hypothermia via $\alpha 1$ adrenergic receptor (Amaro et al., 1996). It has been proposed that hypothermia might enhance CTA formation by extending the associative interval between presentation of taste-conditioned stimuli and the unconditioned aversive effects of $\mathrm{LiCl}$ or other agents (Hinderliter et al., 2002, 2004). Therefore, the elicited CART hypothermia might be adaptive in facilitating CTA formation. Another process enhanced by hypothermia is neuroprotection (Sahuquillo and Vilalta, 2007). Neuronal survival after conditions of decreased oxygen supply (e.g., ischemia) is often increased if core temperature is decreased after the ischemic episode; this phenomenon is observed in rat models of ischemia and is used as a treatment strategy in ischemic patients [for review, see Hoesch and Geocadin (2007) and Nagel et al. (2008) ]. CART is associated with a neuroprotective effect in ischemia (Xu et al., 2006; Jia et al., 2008). Induction of hypothermia could be a part of the mechanism by which CART exerts a neuroprotective effect. Other experiments are needed to evaluate this hypothesis and whether the CARTinduced hypothermia is physiological in nature. Our results indicate that the hypothermia induced by CART is long lasting and shows little tolerance during repeated exposure (data not shown), 


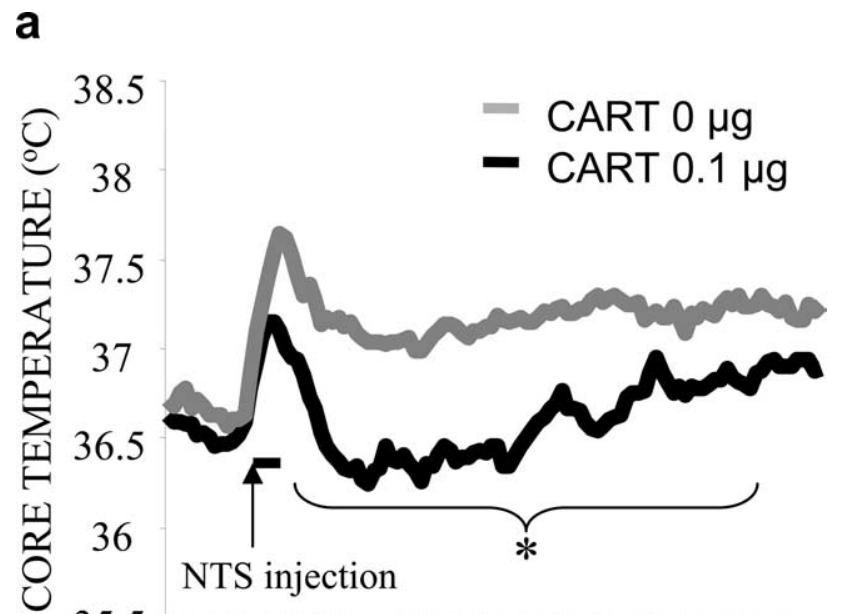

35.5

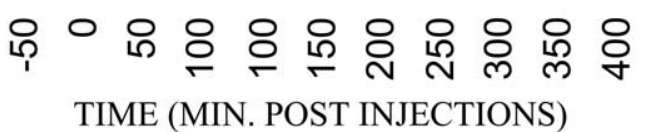

b

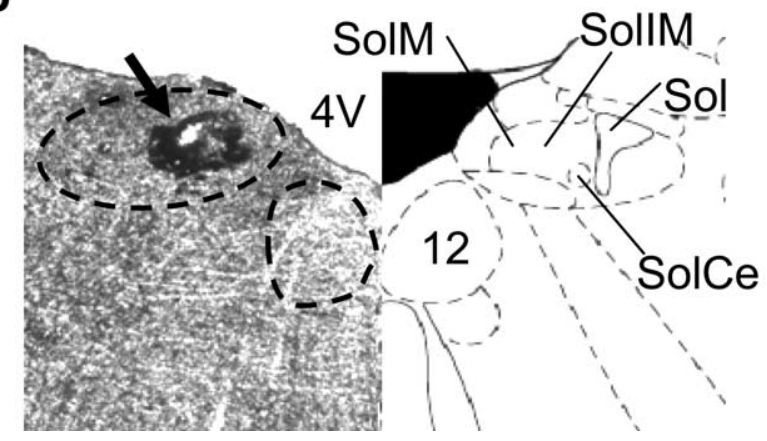

Figure 8. Effect NTS delivery of CART on Tc. $a$, Line graph represents across-rat average parameter measurements through the $8 \mathrm{~h}$ recording period. The bracket outlines $6 \mathrm{~h}$ postinjection period. ${ }^{*} p<0.05$ from vehicle. $b$, Representative NTS injection site (indicated by the arrow). 4V, Fourth ventricle; Sol, nucleus of the solitary tract; SolM, medial nucleus of the solitary tract; SollM, intermedial nucleus of the solitary tract; SolCe, central nucleus of the solitary tract.

two properties highly sought after in potential hypothermiainducing neuroprotective treatments.

\section{References}

Abbott CR, Rossi M, Wren AM, Murphy KG, Kennedy AR, Stanley SA, Zollner AN, Morgan DG, Morgan I, Ghatei MA, Small CJ, Bloom SR (2001) Evidence of an orexigenic role for cocaine- and amphetamine-regulated transcript after administration into discrete hypothalamic nuclei. Endocrinology 142:3457-3463.

Aja S, Schwartz GJ, Kuhar MJ, Moran TH (2001a) Intracerebroventricular CART peptide reduces rat ingestive behavior and alters licking microstructure. Am J Physiol Regul Integr Comp Physiol 280:R1613-R1619.

Aja S, Sahandy S, Ladenheim EE, Schwartz GJ, Moran TH (2001b) Intracerebroventricular CART peptide reduces food intake and alters motor behavior at a hindbrain site. Am J Physiol Regul Integr Comp Physiol 281:R1862-R1867.

Aja S, Robinson BM, Mills KJ, Ladenheim EE, Moran TH (2002) Fourth ventricular CART reduces food and water intake and produces a conditioned taste aversion in rats. Behav Neurosci 116:918-921.

Aja S, Ewing C, Lin J, Hyun J, Moran TH (2006) Blockade of central GLP-1 receptors prevents CART-induced hypophagia and brain c-Fos expression. Peptides 27:157-164.

Amaro S, Monda M, De Luca B (1996) EEG arousal, sympathetic activity, and brown adipose tissue thermogenesis after conditioned taste aversion. Physiol Behav 60:71-75.

Blevins JE, Schwartz MW, Baskin DG (2004) Evidence that paraventricular nucleus oxytocin neurons link hypothalamic leptin action to caudal brain stem nuclei controlling meal size. Am J Physiol Regul Integr Comp Physiol 287:R87-R96.

Broberger C (1999) Hypothalamic cocaine- and amphetamine-regulated transcript (CART) neurons: histochemical relationship to thyrotropinreleasing hormone, melanin-concentrating hormone, orexin/hypocretin and neuropeptide Y. Brain Res 848:101-113.

Broberger C, Holmberg K, Kuhar MJ, Hökfelt T (1999) Cocaine- and amphetamine-regulated transcript in the rat vagus nerve: a putative mediator of cholecystokinin-induced satiety. Proc Natl Acad Sci U S A 96:13506-13511.

Butler AA, Cone RD (2002) The melanocortin receptors: lessons from knockout models. Neuropeptides 36:77-84.

Catalina F, Milewich L, Frawley W, Kumar V, Bennett M (2002) Decrease of core body temperature in mice by dehydroepiandrosterone. Exp Biol Med (Maywood) 227:382-388.

Cone RD (2005) Anatomy and regulation of the central melanocortin system. Nat Neurosci 8:571-578.

Cryan JF, Harkin A, Naughton M, Kelly JP, Leonard BE (2000) Characterization of D-fenfluramine-induced hypothermia: evidence for multiple sites of action. Eur J Pharmacol 390:275-285.

Dhillo WS, Small CJ, Stanley SA, Jethwa PH, Seal LJ, Murphy KG, Ghatei MA, Bloom SR (2002) Hypothalamic interactions between neuropeptide Y, agouti-related protein, cocaine- and amphetamine-regulated transcript and alpha-melanocyte-stimulating hormone in vitro in male rats. J Neuroendocrinol 14:725-730.

Douglass J, Daoud S (1996) Characterization of the human cDNA and genomic DNA encoding CART: a cocaine- and amphetamine-regulated transcript. Gene 169:241-245.

Dun NJ, Dun SL, Kwok EH, Yang J, Chang J (2000) Cocaine- and amphetamine-regulated transcript-immunoreactivity in the rat sympatho-adrenal axis. Neurosci Lett 283:97-100.

Dun SL, Castellino SJ, Yang J, Chang JK, Dun NJ (2001) Cocaine- and amphetamine-regulated transcript peptide-immunoreactivity in dorsal motor nucleus of the vagus neurons of immature rats. Brain Res Dev Brain Res 131:93-102.

Fan W, Dinulescu DM, Butler AA, Zhou J, Marks DL, Cone RD (2000) The central melanocortin system can directly regulate serum insulin levels. Endocrinology 141:3072-3079.

Fan W, Ellacott KL, Halatchev IG, Takahashi K, Yu P, Cone RD (2004) Cholecystokinin-mediated suppression of feeding involves the brainstem melanocortin system. Nat Neurosci 7:335-336.

Flynn FW, Grill HJ (1985) Fourth ventricular phlorizin dissociates feeding from hyperglycemia in rats. Brain Res 341:331-336.

Grill HJ, Norgren R (1978) Chronically decerebrate rats demonstrate satiation but not bait shyness. Science 201:267-269.

Gutiérrez-Juárez R, Obici S, Rossetti L (2004) Melanocortin-independent effects of leptin on hepatic glucose fluxes. J Biol Chem 279:49704-49715.

Hayes MR, Skibicka KP, Grill HJ (2008) Caudal brainstem processing is sufficient for behavioral, sympathetic, and parasympathetic responses driven by peripheral and hindbrain glucagon-like-peptide- 1 receptor stimulation. Endocrinology 149:4059-4068.

Hayes MR, Skibicka KP, Bence KK, Grill HJ (2009) Dorsal hindbrain AMPKinase as an intracellular mediator of energy balance. Endocrinology 150:2175-2182.

Hinderliter CF, Goodhart M, Anderson MJ, Misanin JR (2002) Extended lowered body temperature increases the effective CS-US interval in conditioned taste aversion for adult rats. Psychol Rep 90:800-802.

Hinderliter CF, Musci JA, Pollack CA, Misanin JR, Anderson MJ (2004) Hypothermia modifies the effective CS-US interval in conditioned taste aversion in rats. Neurosci Lett 369:142-144.

Hoesch RE, Geocadin RG (2007) Therapeutic hypothermia for global and focal ischemic brain injury-a cool way to improve neurologic outcomes. Neurologist 13:331-342.

Hwang LL, Chen CT, Li TL, Chiu CZ, Chi SF (2004) Central pressor effects of CART peptides in anesthetized rats. Neuropeptides 38:69-76.

Jaworski JN, Jones DC (2006) The role of CART in the reward/reinforcing properties of psychostimulants. Peptides 27:1993-2004.

Jensen PB, Kristensen P, Clausen JT, Judge ME, Hastrup S, Thim L, Wulff BS, Foged C, Jensen J, Holst JJ, Madsen OD (1999) The hypothalamic satiety peptide CART is expressed in anorectic and non-anorectic pancreatic 
islet tumors and in the normal islet of Langerhans. FEBS Lett 447:139-143.

Jia J, Chen X, Zhu W, Luo Y, Hua Z, Xu Y (2008) CART protects brain from damage through ERK activation in ischemic stroke. Neuropeptides 42: 653-661.

Kong WM, Stanley S, Gardiner J, Abbott C, Murphy K, Seth A, Connoley I, Ghatei M, Stephens D, Bloom S (2003) A role for arcuate cocaine and amphetamine-regulated transcript in hyperphagia, thermogenesis, and cold adaptation. FASEB J 17:1688-1690.

Koylu EO, Couceyro PR, Lambert PD, Ling NC, DeSouza EB, Kuhar MJ (1997) Immunohistochemical localization of novel CART peptides in rat hypothalamus, pituitary and adrenal gland. J Neuroendocrinol 9:823-833.

Koylu EO, Couceyro PR, Lambert PD, Kuhar MJ (1998) Cocaine- and amphetamine-regulated transcript peptide immunohistochemical localization in the rat brain. J Comp Neurol 391:115-132.

Kristensen P, Judge ME, Thim L, Ribel U, Christjansen KN, Wulff BS, Clausen JT, Jensen PB, Madsen OD, Vrang N, Larsen PJ, Hastrup S (1998) Hypothalamic CART is a new anorectic peptide regulated by leptin. Nature 393:72-76.

Kuhar MJ, Adams LD, Hunter RG, Vechia SD, Smith Y (2000) CART peptides. Regul Pept 89:1-6.

Nagel S, Papadakis M, Hoyte L, Buchan AM (2008) Therapeutic hypothermia in experimental models of focal and global cerebral ischemia and intracerebral hemorrhage. Expert Rev Neurother 8:1255-1268.

Nakamura K, Morrison SF (2008) A thermosensory pathway that controls body temperature. Nat Neurosci 11:62-71.

Ritter RC, Slusser PG, Stone S (1981) Glucoreceptors controlling feeding and blood glucose: location in the hindbrain. Science 213:451-452.

Rogge G, Jones D, Hubert GW, Lin Y, Kuhar MJ (2008) CART peptides: regulators of body weight, reward and other functions. Nat Rev Neurosci 9:747-758.

Sahuquillo J, Vilalta A (2007) Cooling the injured brain: how does moderate hypothermia influence the pathophysiology of traumatic brain injury. Curr Pharm Des 13:2310-2322.

Skibicka KP, Grill HJ (2008) Energetic responses are triggered by caudal brainstem melanocortin receptor stimulation and mediated by local sympathetic effector circuits. Endocrinology 149:3605-3616.

Smedh U, Moran TH (2003) Peptides that regulate food intake: separable mechanisms for dorsal hindbrain CART peptide to inhibit gastric emptying and food intake. Am J Physiol Regul Integr Comp Physiol 284:R1418-R1426.
Smith KL, Gardiner JV, Ward HL, Kong WM, Murphy KG, Martin NM, Ghatei MA, Bloom SR (2008) Overexpression of CART in the PVN increases food intake and weight gain in rats. Obesity (Silver Spring) $16: 2239-2244$

Stanley SA, Small CJ, Murphy KG, Rayes E, Abbott CR, Seal LJ, Morgan DG, Sunter D, Dakin CL, Kim MS, Hunter R, Kuhar M, Ghatei MA, Bloom SR (2001) Actions of cocaine- and amphetamine-regulated transcript (CART) peptide on regulation of appetite and hypothalamo-pituitary axes in vitro and in vivo in male rats. Brain Res 893:186-194.

Thim L, Kristensen P, Larsen PJ, Wulff BS (1998) CART, a new anorectic peptide. Int J Biochem Cell Biol 30:1281-1284.

Thim L, Kristensen P, Nielsen PF, Wulff BS, Clausen JT (1999) Tissuespecific processing of cocaine- and amphetamine-regulated transcript peptides in the rat. Proc Natl Acad Sci U S A 96:2722-2727.

Vrang N, Tang-Christensen M, Larsen PJ, Kristensen P (1999a) Recombinant CART peptide induces c-Fos expression in central areas involved in control of feeding behaviour. Brain Res 818:499-509.

Vrang N, Larsen PJ, Clausen JT, Kristensen P (1999b) Neurochemical characterization of hypothalamic cocaine- amphetamine-regulated transcript neurons. J Neurosci 19:RC5.

Wang C, Billington CJ, Levine AS, Kotz CM (2000) Effect of CART in the hypothalamic paraventricular nucleus on feeding and uncoupling protein gene expression. Neuroreport 11:3251-3255.

Xu Y, Zhang W, Klaus J, Young J, Koerner I, Sheldahl LC, Hurn PD, Martínez-Murillo F, Alkayed NJ (2006) Role of cocaine- and amphetamine-regulated transcript in estradiol-mediated neuroprotection. Proc Natl Acad Sci U S A 103:14489-14494.

Yamamoto H, Lee CE, Marcus JN, Williams TD, Overton JM, Lopez ME, Hollenberg AN, Baggio L, Saper CB, Drucker DJ, Elmquist JK (2002) Glucagon-like peptide-1 receptor stimulation increases blood pressure and heart rate and activates autonomic regulatory neurons. J Clin Invest 110:43-52.

Yang SC, Shieh KR, Li HY (2005) Cocaine- and amphetamine-regulated transcript in the nucleus accumbens participates in the regulation of feeding behavior in rats. Neuroscience 133:841-851.

Zheng H, Patterson C, Berthoud HR (2001) Fourth ventricular injection of CART peptide inhibits short-term sucrose intake in rats. Brain Res 896:153-156.

Zheng H, Patterson LM, Berthoud HR (2002) CART in the dorsal vagal complex: sources of immunoreactivity and effects on Fos expression and food intake. Brain Res 957:298-310. 